\title{
VERIFICATION OF MODEL OF CALCULATION OF INTRA-CHAMBER PARAMETERS IN HYBRID SOLID-PROPELLANT ROCKET ENGINES
}

\author{
Ilya S. Zhukov ${ }^{1}$, Boris V. Borisov ${ }^{2,}{ }^{*}$, Sergey S. Bondarchuk ${ }^{1,3}$, and Alexander S. Zhukov ${ }^{1}$ \\ ${ }^{1}$ Tomsk State University, 634050 Tomsk, Russia \\ ${ }^{2}$ Tomsk Polytechnic University, 634050 Tomsk, Russia \\ ${ }^{3}$ Tomsk State Pedagogical University, 634057 Tomsk, Russia
}

\begin{abstract}
On the basis of obtained analytical estimate of characteristics of hybrid solid-propellant rocket engine verification of earlier developed physical and mathematical model of processes in a hybrid solid-propellant rocket engine for quasi-steady-state flow regime was performed. Comparative analysis of calculated and analytical data indicated satisfactory comparability of simulation results.
\end{abstract}

In order to verify mathematical model for calculation of intra-chamber parameters in a hybrid solid-propellant rocket engine [1,2] adequacy assessment of calculation methods was performed using analytical estimation of engine's characteristics for quasi-steady-state flow regime, constant flow section area $S$ and perimeter P of cylindrical grain channel with the radius $\mathrm{r}$. Other sufficiently accurate solutions of this problem were not obtained.

For abovementioned assumptions the change of oxidizer flow along the grain channel of a hybrid engine can be described by the following equation:

$$
\frac{d}{d x}(\varrho u S)=-\mathrm{P} \alpha_{o x} \varrho_{f} a(\varrho u)^{v}
$$

where $\mathrm{Q}, u$ - oxidizer density and flow rate;

$a, \nu$ - burning rate law constants; $\mathrm{Q}_{f}$ - fuel density; $\alpha_{\mathrm{ox}}=m_{\mathrm{ox}} / m_{f}$ - ratio of "consumed" oxidizer mass flow $m_{\mathrm{ox}}$ to the mass of fuel $m_{f}$ in the process of combustion.

Solution of equation (1) regarding oxidizer flow at any channel point (section) is as follows

$$
\left.(\varrho u)\right|_{x}=\left[(\varrho u)_{0}^{1-v}-\varphi x\right]^{1 /(1-v)}, \varphi=\frac{2}{r} \alpha_{o x} \varrho_{f}(1-v) a
$$

where $(\varrho u)_{0}=\left(m_{o x}^{i n}\right) / S$ - mass flow rate of oxidizer injection $\left(m_{o x}^{i n}-\right.$ total oxidizer consumption).

As it is implied from equation (2) oxidizer mass consumer for combustion $m_{\mathrm{ox}}$ can be determined from the following relation

\footnotetext{
${ }^{*}$ Corresponding author: bvborisov@tpu.ru
} 


$$
m_{o x}=\left\{\begin{array}{l}
m_{o x}^{i n}-S \cdot\left[(\varrho u)_{0}^{1-v}-\varphi L\right]^{1 /(1-v)}, \operatorname{ec\imath u}(\varrho u)_{0}^{1-v}>\varphi L \\
m_{o x}^{i n}, \operatorname{ec\imath u}(\varrho u)_{0}^{1-v} \leq \varphi L
\end{array}\right.
$$

Mass of fuel $m_{f}$ consumed in the process of combustion is equal to $m_{f}=m_{o x} / \alpha_{o x}$ and the total mass of combustion products and "unused" oxidizer is equal to $m_{\Sigma}=m_{o x}^{i n}+m_{f}$.

Thermodynamic characteristics of the mixture (gas constant $\mathrm{R}$ and isobaric heat capacity $C_{p}$ ) are determined additively using mass individual characteristics of oxidizer gas $\left(R_{o x}, C_{p_{o x}}\right)$ and combustion products $\left(R_{f}, C_{p_{f}}\right)$

$$
R=c_{o x} R_{o x}+c_{f} R_{f}, C_{p}=c_{o x} C_{p_{o x}}+c_{f} C_{p_{f}},
$$

where mass fractions of "unused" oxidizer $c_{o x}$ and combustion products $c_{f}$ are determined by the following relations

$$
c_{o x}=\frac{m_{o x}^{i n}-m_{o x}}{m_{\Sigma}}, c_{f}=\frac{m_{f}+m_{o x}}{m_{\Sigma}}=1-c_{o x} .
$$

The temperature of mixture of combustion products and "unused" oxidizer can be determined from the law of conservation of energy:

$$
\frac{\gamma}{\gamma-1} R T m_{\Sigma}=\left(m_{f}+m_{o x}\right)\left(\frac{\gamma}{\gamma-1} R T\right)_{f}-m_{o x}^{i n}\left(\frac{\gamma}{\gamma-1} R\right)_{o x}\left(\tilde{T}-T_{o x}\right) .
$$

The first member in the right part of equation (3) describes energy input due to fuel combustion products with the temperature $T_{f}$ entering the flow. The last member of the right part of this equation represents energy losses due to heating of oxidizer gas from its initial temperature $T_{o x}$ to some average value $\tilde{T}$. At a first approximation it can be taken as $\tilde{T}=\left(T_{f}+T_{o x}\right) / 2$.

Then from the balance of mass of gas supplied to combustion chamber $m_{o x}^{i n}$ and combustion products $m_{\Sigma}$ taking into account the fact that they are equal to flow rate $G$ through the nozzle block with throat area $S_{*}$ in case of critical flow, pressure $p$ in combustion chamber can be determined

$$
p=\frac{m_{\Sigma}}{S_{*} \mathrm{G}_{*}(\gamma)} \sqrt{R T}, \quad G=S_{*} \mathrm{G}_{*}(\gamma) \cdot \frac{p}{\sqrt{R T}}=m_{\Sigma}, \quad \mathrm{G}_{*}(\gamma)=\sqrt{\gamma\left(\frac{2}{\gamma+1}\right)^{\frac{\gamma+1}{\gamma-1}}} .
$$

Comparison of numerical calculation results and analytical estimation data obtained using the abovementioned relationships was performed for various levels of oxidizer supply to combustion chamber of hybrid solid-propellant rocket engine with the following parameters.

Initial data for calculation

Engine geometry parameters

Channel radius $r=1 \mathrm{~cm}$;

Throat area $S_{*}=0.79 \mathrm{~cm}^{2}$;

Fuel grain length $L=50 \mathrm{~cm}$.
Oxidizer parameters

Gas temperature $T_{o x}=300 \mathrm{~K}$;

Adiabatic index $\gamma_{o x}=1.4$;

Gas constant $R_{o x}=296 \mathrm{~J} / \mathrm{kg} / \mathrm{K}$.

Fuel parameters 
Burning rate law $a=0.07 \mathrm{~mm} / \mathrm{s}, v=0.65$;

Fuel density $\varrho_{f}=1000 \mathrm{~kg} / \mathrm{m} 3$;

Gas constant of combustion products $R_{f}=320 \mathrm{~J} / \mathrm{kg} / \mathrm{K}$;

Adiabatic index of combustion products $\gamma_{f}=1.22$;

Fuel-oxidizer ratio $\alpha_{o x}=2.7$;

Burning temperature $T_{f}=3000 \mathrm{~K}$.

Fig.1 illustrates pressure distribution along the relative channel length for $m_{o x}^{i n}=0.2 \mathrm{~kg} / \mathrm{s}$.

Relatively smooth pressure profile (power-law type) typical for initial conditions of engine operation is observed. It should be noted that for initial data as well as for other values of oxidizer flow rate the profile is transformed smoothly due to non-uniform fuel burnout and as the front part of fuel grain burns completely a pressure peak is formed and moves together with fuel burnout boundary.

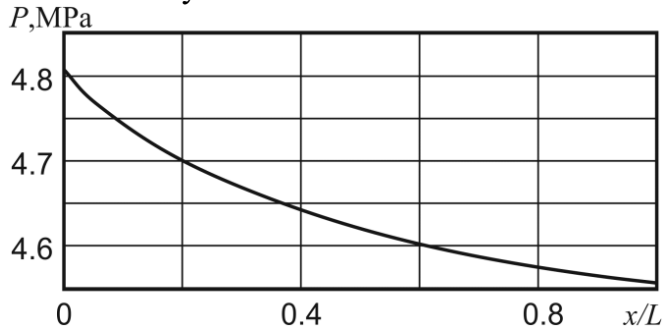

Fig. 1. Pressure distribution along the channel length.

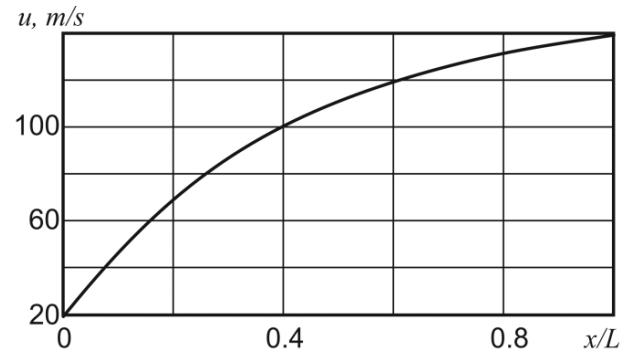

Fig. 2. Gas flow rate distribution along the channel length.

Table 1. - Results of comparison of numerical and analytical data.

\begin{tabular}{|c|c|c|c|c|c|c|c|c|}
\hline \multirow{2}{*}{$\begin{array}{l}m_{o x}^{\text {in }} \\
\mathrm{kg} / \mathrm{s}\end{array}$} & \multicolumn{2}{|c|}{$p, \mathrm{MPa}$} & \multicolumn{2}{c|}{$\left.c_{\text {ox }}\right|_{x=L}$} & \multicolumn{2}{c|}{$\left.T\right|_{x=L}, K$} & \multicolumn{2}{c|}{$G, \mathrm{~kg} / \mathrm{s}$} \\
\cline { 2 - 9 } & num & theor & num & theor & num & theor & num & theor \\
\hline 0.10 & 2.33 & 2.40 & 0.002 & 0.002 & 2385 & 2523 & 0.137 & 0.137 \\
\hline 0.20 & 4.59 & 4.71 & 0.029 & 0.026 & 2361 & 2480 & 0.271 & 0.271 \\
\hline 0.35 & 7.84 & 7.97 & 0.070 & 0.068 & 2326 & 2404 & 0.467 & 0.468 \\
\hline 0.80 & 16.87 & 16.91 & 0.163 & 0.159 & 2233 & 2235 & 1.034 & 1.035 \\
\hline 1.00 & 20.73 & 20.63 & 0.189 & 0.187 & 2206 & 2180 & 1.281 & 1.281 \\
\hline 2.00 & 38.88 & 37.95 & 0.283 & 0.281 & 2095 & 1992 & 2.481 & 2.482 \\
\hline
\end{tabular}

\begin{tabular}{|c|c|c|c|c|}
\hline$\Delta, \%$ & 1.70 & 3.01 & 3.36 & 0.06 \\
\hline
\end{tabular}

$\Delta-$ mean difference between parameter values.

The results of comparison of numerical and analytical data ("num" - numerical calculation results; "theor" - analytical estimation data) for various levels of oxidizer supply to combustion chamber of hybrid solid-propellant rocket engine are given in Table 1. 
Mean difference between values of parameters determining the process (Table 1) does not exceed $3.5 \%$ for selected configuration.

Thus, an analytical estimate of engine's characteristics for verification of developed physical and mathematical model of processes in a hybrid solid-propellant rocket engine for quasi-steady-state flow regime, constant flow section area and constant perimeter of working surface of cylindrical grain channel is given in this paper. Performed parametric comparative analysis of calculated and analytical data indicated more than satisfactory comparability of results of numerical calculation and analytical estimation - mean difference between values of parameters determining the process does not exceed $3.5 \%$ for selected configuration.

\section{Acknowledgments}

This research was supported by the Ministry of Education and Science of the Russian Federation under the Federal Target Program "Research and development on priority directions of scientific-technological complex of Russia for 2014-2020”, the agreement No. 14.578.21.0034, unique identifier PNI RFMEFI57814X0034.

\section{References}

1. S.S. Bondarchuk, A.B. Vorozhtsov, A.S. Zhukov, B.V. Borisov., Russian Phys. 57, 12 (2015)

2. S.S.Bondarchuk, A.B. Vorozhtsov, A.S. Zhukov, I.A. Zhukov, S.A. Vorozhtsov, V.V. Promakhov The Proceedings of the 46th International Annual Conference of the Fraunhofer ICT: Energetic Materials. Performance, Safety and System Applications. Karlsruhe, Germany (2015) 